\title{
Comparative Analysis of Various Wireless Multimedia Sensor Networks for Telemedicine
}

\author{
Nafiz Imtiaz Bin Hamid ${ }^{1}$, Mugumya Twarik Harouna ${ }^{2}$, Nafiu Salele ${ }^{2}$, Rammah Muhammad ${ }^{2}$ \\ ${ }^{1}$ Department of Electrical and Electronic Engineering, ${ }^{2}$ Department of Technical and Vocational Education \\ Islamic University of Technology (IUT), Board Bazar, Gazipur-1704, Bangladesh.
}

\begin{abstract}
The increasing need for better healthcare is one of the fiercest challenges faced by both developed and developing countries. The aging population has led to shortage of specialists in the medical field, depriving remote and underprivileged areas of better healthcare. The advances in information and communication technologies offer hope of technologies that have a great potential to reduce mortality and morbidity while improving the healthcare service delivery. Telemedicine is a magnificent tool that bridges the gap between the specialists and patients, bringing specialty care to the location of the patient in life time. In this paper, a comparative review of some of the existing telemedicine architectures has been presented. It is followed by solutions for some ongoing challenges in Wireless Multimedia Sensor Network (WMSN) considering telemedicine applications. Finally a WMSN enabled telemedicine architecture integrated with a 4G wireless cellular network is proposed.
\end{abstract}

\section{General Terms}

WMSN, Telemedicine, Ultra-Wide Band (UWB).

\section{Keywords}

Physiological Monitors (PM), Relay Points (RP), Zigbee.

\section{INTRODUCTION}

Recently there has been a prominent growth in wireless communication, networking and sensing technologies and they are merging to provide new and evolving technologies like WMSNs. A WMSN can be considered as a network of wirelessly interconnected sensors capable of ubiquitously retrieve video and audio streams, still images as well as physical data from the environment. A WMSN is made up of video and audio sensors, scalar sensors, multimedia processing hubs, storage hubs, sink and a gateway. There are typically three different reference architectures for WMSNs; namely: a) single-tier flat, homogeneous sensors, distributed processing, centralized storage; b) single-tier clustered, heterogeneous sensors, centralized processing, centralized storage; c) multitier, heterogeneous sensors, distributed processing, distributed storage [1]. Wireless Sensor Networks (WSNs) were initially developed for military application but currently they are being utilized for civil purposes, a number of applications have been developed; they include traffic monitoring, habitat sensing and seismic monitoring, person locator service in fire detection and tracking application, efficient industrial process control, and telemedicine among others. The main focus of this paper is to cover and compare various telemedicine centric WMSN architectures, highlight underlying challenges and propose a new architecture.

\section{TELEMEDICINE}

Telemedicine is a growing application of WMSN, it is neither a technology nor a separate medical specialty, but an application. The World Health Organization has adopted the description of Telemedicine as "The delivery of health care services, where distance is a critical factor, by all health care professionals using information and communication technologies for the exchange of valid information for diagnosis, treatment and prevention of disease and injuries, research and evaluation, and for the continuing education of health care providers, all in the interests of advancing the health of individuals and their communities"[2]. Telemedicine is sometimes referred to as telehealth and telecare. The core benefit of telemedicine is saving and assuring patients' access to care when they need it and when time is critical for diagnosing and treating serious conditions.

Telemedicine can be mainly classified into three categories: Store and forward telemedicine, remote monitoring telemedicine and real-time (live) telemedicine [3]. In store and forward telemedicine, medical data and images are retrieved from the patient using medical sensors, and then sent through a secure connection to a medical specialist who examines the data and gives the recommendation. Medical data may include EEG, ECG, EMG, EOG and ERG signals, heart beat rate, and blood pressure, and the medical images may include CT, SPECT, MRI and PET. Store and forward telemedicine is very important in many medical situations, for example in reading a pediatric EEG, this EEG is complex, due to the uniqueness of the electrical signals from the baby's brain and it requires a specialist to interpret it, who may not be available locally. In Remote monitoring telemedicine, medical data is collected periodically and continuously from the patient and integrated automatically into the patient care record. It allows long-term care and trend analysis by monitoring vital signs of a patient remotely using various technological devices. It's primarily used for monitoring chronic diseases, thus reducing the length of hospital stay. Live telemedicine involves video conferencing between the patients and the specialist doctor [3]. This is usually facilitated by a two way interactive television (IATV).

The following section gives a comparative discussion on some of the existing architectures for telemedicine. 


\section{OVERVIEW AND COMPARISON OF THE EXISTING ARCHITECTURES}

There are several wireless healthcare researches and projects that have been designed to provide continuous patient monitoring in hospital and during disaster management, real time collection of medical data in-house assisted-living as well as mobile monitoring. The following section gives an overview and comparison of the exiting architectures of wireless medical sensor networks. These include MEDiSN, CodeBlue, MASN, AlarmNet and MobiCare.

\subsection{MEDiSN}

MEDiSN[4] was designed at John Hopskin University, especially for patients' monitoring in hospital and during disaster events. It consists of multiple Physiological Monitors (PMs) which are battery-powered motes that are equipped with sensors for measuring patients' physiological data such as ECG, pulse rate, blood oxygen level etc. PMs temporarily store collected measurements and transmit them after encrypting and signing them. MEDiSN architecture incorporates distinct Relay Points (RPs) which self organize into bidirectional wireless trees connecting the PMs to one or more Gateways. Traffic flowing in both directions is protected using hop-by-hop retransmissions that counter the effects of packet collisions and corruptions. PMs can be mobile while the RPs are stationary in fixed positions. RPs can use the electricity grid in hospital deployments, while in disaster events batteries can power RPs for multiple days. Figure 1 shows an illustrative overview of MEDiSN architecture [5].

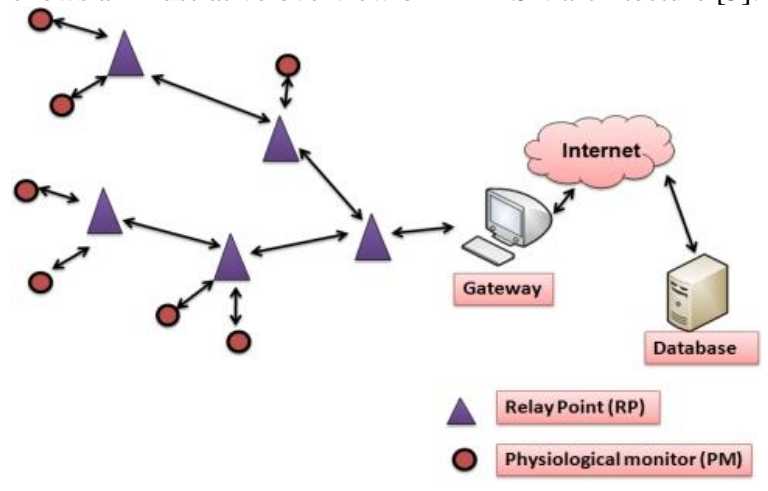

Figure 1: MEDiSN architecture

\subsection{CodeBlue}

CodeBlue[6] is a research project on medical sensor network developed at the Harvard University Sensor Lab. In this architecture, medical sensors are placed on the patient's body to sense medical data and transmit it wirelessly to the medical care givers for further analysis. It is based on a publish/subscribe routing framework, allowing multiple sensor devices to relay data to all receivers that have registered an interest in that data. This communication model fits naturally with the needs of medical applications where a number of caregivers may be interested in sensor data from overlapping groups of patients. Figure 2 shows an illustrative overview of CodeBlue architecture [5].

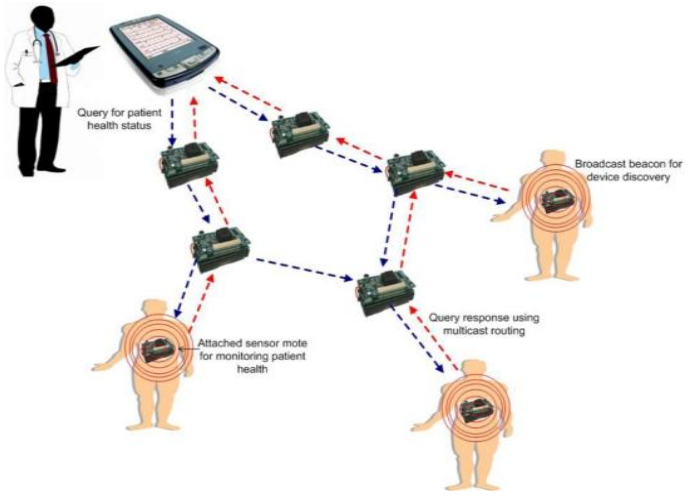

Figure 2: CodeBlue architecture

\subsection{MASN}

The robust Medical Ad hoc Sensor Network (MASN) is a practical hardware and software platform developed at Rochester Institute of Technology, USA[7]. It was designed to perform real-time collection of medical data. MASN adopts a reliable cluster-based communication scheme as its routing protocol for transmitting data. MASN consists of large amount of wireless ECG communication units. Each unit is called a "mobile platform". These mobile platforms are essentially the wearable ECG devices that would be placed on the patients in order to offer continuous monitoring of the patients' vital signs. Figure 3 shows an illustrative overview of MASN architecture [7].

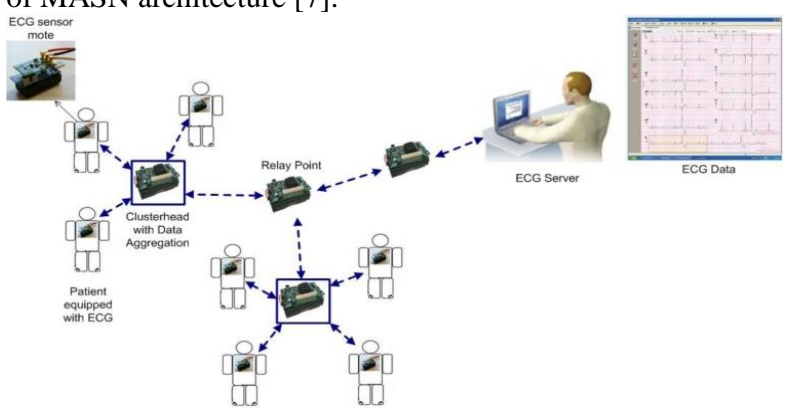

Figure 3: MASN architecture

\subsection{AlarmNet}

A Wireless sensor networks for assisted-living and residential monitoring was developed at the University of Virginia, integrates environmental and physiological sensors in a scalable, heterogeneous architecture [8]. A query protocol allows real-time collection and processing of sensor data by user interfaces and back-end analysis programs. Figure 4 shows an illustrative overview of AlamNet architecture [5].

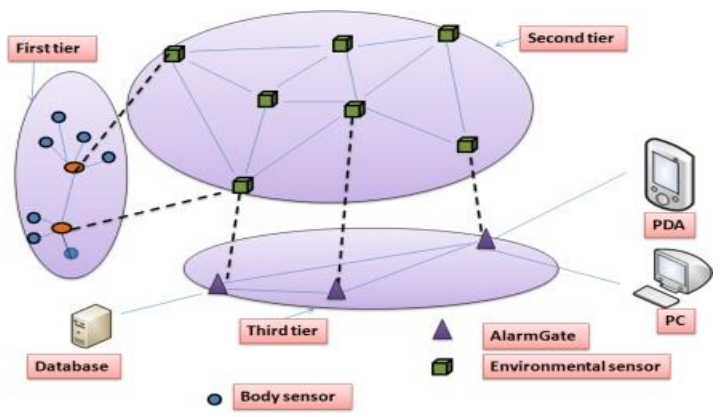

Figure 4: AlarmNet architecture 


\subsection{MobiCare}

MobiCare[9] is a remote wireless patient monitoring system designed at the University of Wisconsin, Madison, USA. It consists of three important building blocks: a body sensor network (BSN) consisting of wearable sensors and actuators with wireless inter-connections; a BSN Manager (also called MobiCare client) that connects the BSN to an 'always-on' wide-area communication interface using wide-area cellular wireless link; and back-end infrastructure support (MobiCare servers) at healthcare providers side to implement necessary healthcare functionalities. Figure 5 shows an illustrative overview of MobiCare architecture [5].

Table 1.Architectural comparison

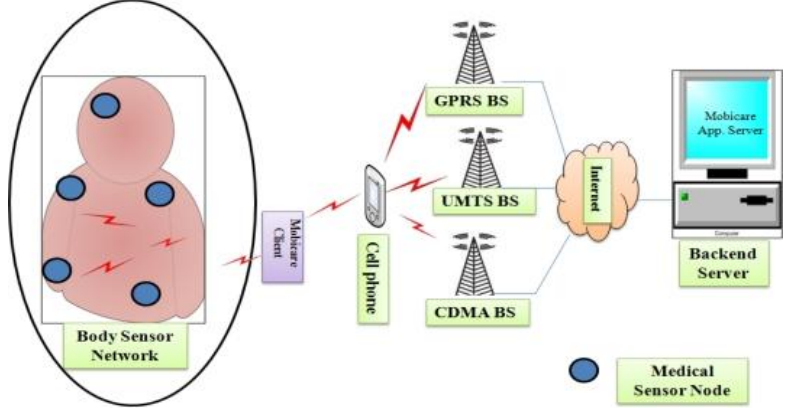

Figure 5: MobiCare architecture

\begin{tabular}{|c|c|c|c|c|c|}
\hline Parameter & MEDiSN & CodeBlue & MASN & AlarmNet & MobiCare \\
\hline $\begin{array}{l}\text { Operational } \\
\text { Environme } \\
\text { nt }\end{array}$ & $\begin{array}{l}\text { The operational } \\
\text { environment constitutes a } \\
\text { Dedicated Wireless } \\
\text { Sensor Network in } \\
\text { Hospital Deployment } \\
\text { with RPs and PMs }\end{array}$ & $\begin{array}{lr}\text { CodeBlue prototype } \\
\text { was validated on } 30 \\
\text { Node Ad Hoc Sensor } \\
\text { Network Test-Bed, } \\
\text { demonstrating } \\
\text { scalability } \\
\text { robustness }\end{array}$ & $\begin{array}{l}\text { Medical Ad } \\
\text { Hoc Sensor } \\
\text { Network deployed } \\
\text { in Nursing homes }\end{array}$ & $\begin{array}{l}\text { Scalable and } \\
\text { heterogeneous } \\
\text { architecture } \\
\text { integrating ESs and } \\
\text { PMs in assisted-living } \\
\text { and home environment }\end{array}$ & $\begin{array}{l}\text { A remote wireless } \\
\text { patient } \\
\text { monitoring } \\
\text { consisting of } \\
\text { BSN, MobiClient } \\
\text { and MobiCare } \\
\text { Server. }\end{array}$ \\
\hline $\begin{array}{l}\text { Supported } \\
\text { Application }\end{array}$ & $\begin{array}{l}\text { Applied in medical } \\
\text { emergency detection for } \\
\text { patients monitored in } \\
\text { hospitals and disaster } \\
\text { scenes. }\end{array}$ & $\begin{array}{l}\text { It was applied in } \\
\text { Medical Care and } \\
\text { Disaster management }\end{array}$ & $\begin{array}{lr}\text { Real-time } & \text { remote } \\
\text { cardiac } & \text { patient } \\
\text { monitoring } & \text { and } \\
\text { collection of ECG } \\
\text { Data }\end{array}$ & $\begin{array}{l}\text { Patient health } \\
\text { monitoring in the } \\
\text { assisted-living and } \\
\text { home environment }\end{array}$ & $\begin{array}{l}\text { Wide-Area } \\
\text { Mobile patient } \\
\text { monitoring }\end{array}$ \\
\hline $\begin{array}{l}\text { Reliability } \\
\text { Mechanism }\end{array}$ & $\begin{array}{l}\text { Message } \\
\text { Middleware (MOM), } \\
\text { which was JMS-based } \\
\text { has been selected to run } \\
\text { on the Gateway. While } \\
\text { the back-end server is } \\
\text { responsible for storing, } \\
\text { routing, and } \\
\text { retransmitting messages. }\end{array}$ & $\begin{array}{l}\text { CodeBlue was designed } \\
\text { to provide for reliable } \\
\text { transmission of critical } \\
\text { data through content- } \\
\text { specific prioritization } \\
\text { and dynamic scaling of } \\
\text { transmission power. }\end{array}$ & $\begin{array}{l}\text { Enhanced cluster- } \\
\text { based, energy-aware } \\
\text { data transmission } \\
\text { has been proposed, } \\
\text { where the ECG data } \\
\text { are reliably relayed } \\
\text { to the sink in the } \\
\text { form of aggregated } \\
\text { data packets. }\end{array}$ & $\begin{array}{l}\text { Three-Tier } \\
\text { Architecture with } \\
\text { Mobile Body network, } \\
\text { Emplaced Sensor } \\
\text { Network and IP } \\
\text { Network }\end{array}$ & $\begin{array}{l}\text { MobiCare } \\
\text { designed a secure } \\
\text { reliable dynamic } \\
\text { code update } \\
\text { functionality that } \\
\text { is implemented as } \\
\text { part of each } \\
\text { MobiCare client } \\
\text { and sensor device }\end{array}$ \\
\hline $\begin{array}{l}\text { Scheme for } \\
\text { Energy } \\
\text { Efficiency }\end{array}$ & $\begin{array}{l}\text { The division of } \\
\text { functionality between } \\
\text { acquiring and relaying } \\
\text { data enables PMs to } \\
\text { achieve low energy } \\
\text { consumption, through } \\
\text { duty cycling their radios }\end{array}$ & $\begin{array}{l}\text { CodeBlue uses } \\
\text { Berkeley Mica2 sensor } \\
\text { nodes which include a } \\
\text { low-power, single-chip } \\
\text { radio with batteries that } \\
\text { will last for up to a } \\
\text { week of continuous } \\
\text { running. Employing } \\
\text { duty-cycling, the device } \\
\text { can drop to a very low } \\
\text { power sleep state of } \\
10 \mu \mathrm{A}\end{array}$ & $\begin{array}{l}\text { MASN Proposed an } \\
\text { Energy-aware } \\
\text { cluster formation } \\
\text { scheme using event } \\
\text { triggered energy } \\
\text { level determination } \\
\text { of sensor nodes }\end{array}$ & $\begin{array}{l}\text { Context-aware and } \\
\text { Open Power } \\
\text { Management Scheme } \\
\text { (COPM) module was } \\
\text { designed, where some } \\
\text { nodes are plugged into } \\
\text { the wall and others } \\
\text { operate on batteries }\end{array}$ & $\begin{array}{l}\text { Propose the use } \\
\text { of low-power, } \\
\text { low-frequency } \\
\text { wireless sensor } \\
\text { developed at } \\
\text { Harvard } \\
\text { University using } \\
\text { (using r the } \\
\begin{array}{l}\text { Berkeley MICA2 } \\
\text { mote) }\end{array}\end{array}$ \\
\hline $\begin{array}{l}\text { Routing } \\
\text { Methodolo } \\
\text { gy }\end{array}$ & $\begin{array}{l}\text { Many-to-one and one-to- } \\
\text { one communication } \\
\text { between PMs and RPs. } \\
\text { Collection Tree Protocol } \\
\text { (CTP) was also used by } \\
\text { the RPs }\end{array}$ & $\begin{array}{l}\text { Based on the Adaptive } \\
\text { Demand-Driven } \\
\text { Multicast Routing } \\
\text { (ADMR) protocol in } \\
\text { which sensors publish } \\
\text { relevant data to a } \\
\text { specific channel and } \\
\text { end-user devices } \\
\text { subscribe to channels of } \\
\text { interest }\end{array}$ & $\begin{array}{l}\text { Used Intra-Cluster } \\
\text { and Inter-Cluster } \\
\text { Data Relay routing } \\
\text { scheme }\end{array}$ & $\begin{array}{l}\text { Single hop at the first } \\
\text { Tier, multi-hop at the } \\
\text { second tier (i.e., } \\
\text { Shortest-path-first } \\
\text { routing protocol) }\end{array}$ & $\begin{array}{l}\text { Application layer } \\
\text { standard HTTP } \\
\text { POST protocol }\end{array}$ \\
\hline $\begin{array}{l}\text { Techniques } \\
\text { for } \\
\text { Mobility } \\
\text { Support }\end{array}$ & $\begin{array}{l}\text { During mobility PM } \\
\text { sends its data to the } \\
\text { stationed RP that shares } \\
\text { the best link with it }\end{array}$ & $\begin{array}{l}\text { A tracking system } \\
\text { named MoteTrack } \\
\text { which operates in an } \\
\text { entirely decentralized, } \\
\text { robust fashion, provide } \\
\text { good location accuracy }\end{array}$ & $\begin{array}{l}\text { MASN cannot } \\
\text { achieve real-time } \\
\text { data collection } \\
\text { (delay > } 10 \mathrm{~s} \text { ) if the } \\
\text { users move quickly } \\
\text { such as at } 30 \mathrm{mph}\end{array}$ & $\begin{array}{l}\text { Emplaced Sensors } \\
\text { (ES) maintain } \\
\text { connections with } \\
\text { mobile body as they } \\
\text { move through the } \\
\text { living space }\end{array}$ & $\begin{array}{l}\text { Used always-on } \\
\text { wide-area cellular } \\
\text { wireless } \\
\text { communication } \\
\text { interface }\end{array}$ \\
\hline
\end{tabular}




\section{CHALLENGES FACED}

There are several challenges faced by WMSN applications, they include: QoS requirements, scalable and flexible architectures and protocols to support heterogeneous applications, localized processing and data fusion, energy efficiency design, reliability and fault tolerance, multimedia coverage, high bandwidth demand, and more [1]. Many researches have focused on power consumption, but our main concern in this paper is the high bandwidth demand required for video and audio streams in live telemedicine. The following section discusses a promising solution for bandwidth hungry WMSN enabled telemedicine applications.

\section{UWB AS A SOLUTION}

The real-time video conferencing makes telemedicine application a high bandwidth hungry application of WMSN. UWB is a recently approved low power and high speed, shortrange wireless communication standard based on IEEE 802.15.3, oriented to high-bandwidth multimedia links [10]. A comparison between UWB and Zigbee, another promising technology for wireless sensor network applications is presented in the Table 2.

Table 2.Comparison of UWB and Zigbee technology

\begin{tabular}{|c|c|c|}
\hline Parameter & UWB & Zigbee \\
\hline $\begin{array}{c}\text { IEEE } \\
\text { Specification }\end{array}$ & 802.15 .3 & 802.15 .4 \\
\hline $\begin{array}{l}\text { Typical Range } \\
\text { (Meters) }\end{array}$ & 10 & 10 \\
\hline $\begin{array}{c}\text { Power } \\
\text { Consumption }\end{array}$ & Very little & Low \\
\hline Spectrum $(\mathrm{GHz})$ & $3.1-10.6$ & 2.4 \\
\hline Bandwidth & High & Low \\
\hline Data rate & $\begin{array}{c}110-480 \\
\text { Mbps }\end{array}$ & $\begin{array}{c}20-240 \\
\text { Kbps }\end{array}$ \\
\hline $\begin{array}{c}\text { Channel } \\
\text { bandwidth }\end{array}$ & $500 \mathrm{MHz}$ & $\begin{array}{c}0.3 \mathrm{MHz}- \\
2 \mathrm{MHz}\end{array}$ \\
\hline $\begin{array}{l}\text { Energy } \\
\text { efficiency }\end{array}$ & Very High & Low \\
\hline Data protection & $\begin{array}{l}\text { 32-bit cyclic } \\
\text { redundancy } \\
\text { check }\end{array}$ & $\begin{array}{l}\text { 16-bit cyclic } \\
\text { redundancy } \\
\text { check }\end{array}$ \\
\hline $\begin{array}{c}\text { Typical } \\
\text { Applications }\end{array}$ & $\begin{array}{c}\text { Industrial } \\
\text { control and } \\
\text { monitoring, } \\
\text { sensor } \\
\text { networks, etc. }\end{array}$ & $\begin{array}{c}\text { Streaming } \\
\text { video, home } \\
\text { entertainment } \\
\text { applications }\end{array}$ \\
\hline
\end{tabular}

\subsection{Low Electromagnetic Radiation}

Low electromagnetic radiation is one of the notable features of UWB that makes it viable for telemedicine application. As a result, it has proved to be harmless to human body and has almost no detrimental effect on the environment [11]. It makes UWB suitable for health care applications.

\subsection{Coexistence and Reduced Interference}

At the same time UWB can coexist with other wireless technologies due to its low power spectral density. This feature prevents interference on other wireless services.

\subsection{Tackling High Bandwidth Demand}

Telemedicine application involves real-time video conferencing between the patient and the specialist to allow proper diagnosis, the video conferencing requires a high bandwidth for multimedia streaming, and this demand can be met by UWB technology. As seen in Table 2, the data rate of UWB is 2000 times higher than that of Zigbee. To maintain acceptable QoS, Zigbee cannot support many devices due to the low data rate. For example in [12], 24Kbps was taken as the required data rate for ECG monitoring application, but Zigbee can at best provide $240 \mathrm{Kbps}$, implying that a maximum of 10 devices could be connected. Again, at least $640 \mathrm{Kbps}$ is required to allow high quality diagnostic video stream (MPEG-4 format) and a minimum $768 \mathrm{kbps}$ for Normal diagnostic video(MPEG-2 format), these data rates cannot be provided by Zigbee devices, UWB can support many devices using the "peer to peer" mechanism $[12,13]$ while utilizing the available data rates. This makes UWB a viable solution for high bandwidth demand in live telemedicine application.

\section{PROPOSED ARCHITECTURE}

The structure of our proposed architecture shown in Figure 6 is created by integrating a WMSN with a $4 \mathrm{G}$ cellular network. The WMSN provides a platform for acquiring medical data from the patients and sends it through a $4 \mathrm{G}$ based wireless cellular network to the specialist for analysis and diagnosis. The architecture is made up of cameras, speakers, interactive television, different biomedical sensors (handheld and wearable devices), local storage server and a gateway. Biomedical sensors include digital stethoscope for measuring the heartbeat, ophthalmoscope and others. It provides realtime consultation and continuous monitoring of the patients physiological data regardless of location provided the location has a 4G wireless network coverage needed for the multimedia streaming for transmitting the required data to the specialist at a distant location.

The 4G cellular network provides the long range telemedicine facilities between the specialist and patient's healthcare center, thus providing global services. 


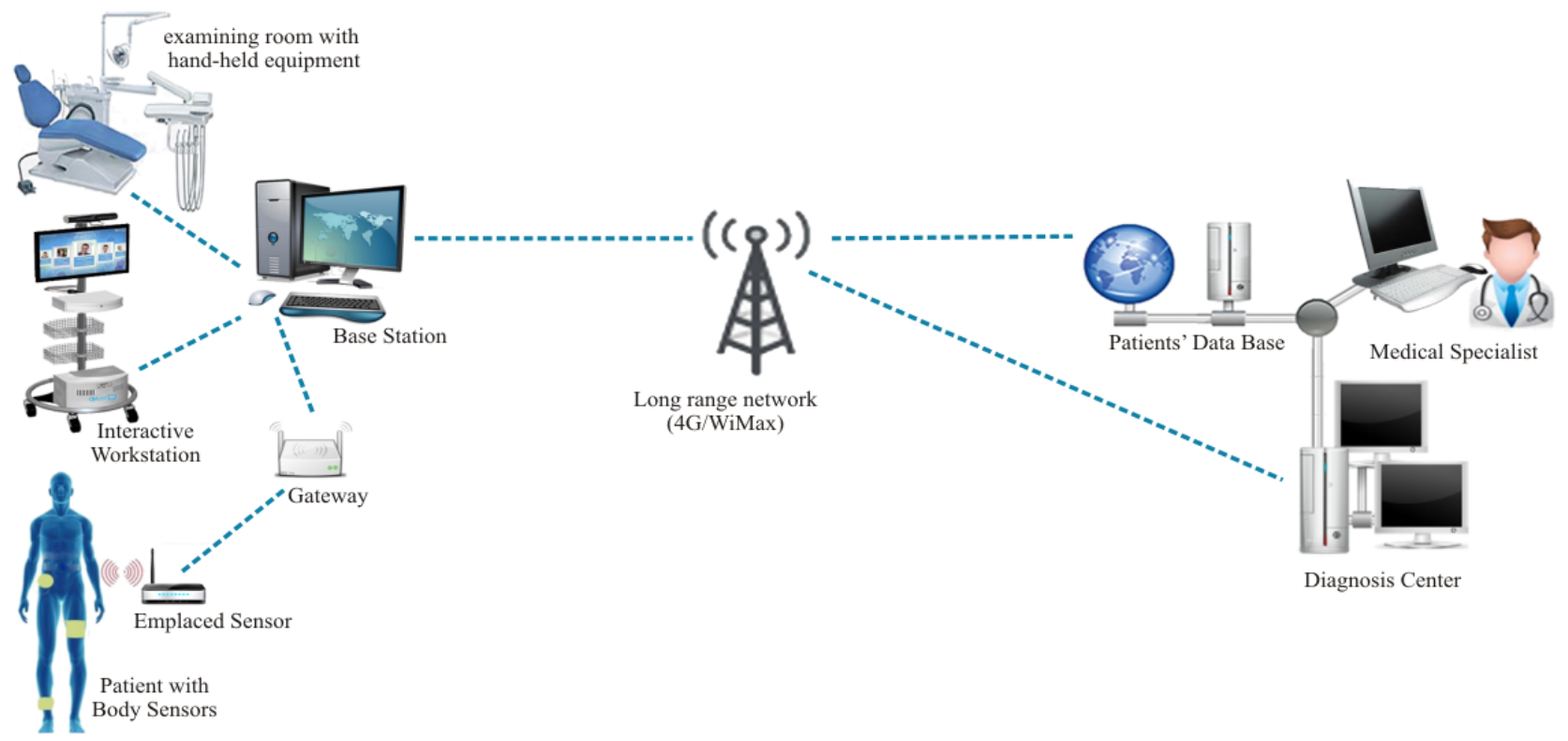

Figure 6: Architecture of the proposed network

\subsection{How it Works}

The proposed architecture supports heterogeneous networking. Using UWB network, it forms an island of sensors (WMSN), and these different sensors collect the required data from the patient depending on the telemedicine type (i.e. live, store and forward, monitoring telemedicine). The medical data is processed (compressed, encrypted, etc) and then it is sent to the gateway (the only IP addressable component of the WMSN) and it's also stored locally in the storage server. The gateway provides the connectivity and integration with the WiMAX network. The WiMAX network transmits the data over a long communication range to the specialist in another area. The data is received at the specialist side, the data is checked if it's valid and then after it can be processed (decrypted, decompressed), Then the data can be analyzed and then used for diagnosis and treatment.

\subsection{Distinctive Features}

The architecture offers an automatic process for accomplishing tasks.

- The first feature is the monitoring vital signs of a patient with a chronic disease are collected periodically, processed and saved into the patient's medical record locally. For some special cases, for example a stroke patient, a camera is also used in monitoring. If the readings recorded deviates from the safety margin, an alert will be sent to the doctor. A biometric scheme will also be used to identify the patient and authentic data.

- The second feature of the system is the live telemedicine; Face to face consultation is carried out using the interactive workstation, the physiological data of the patient is measured on real-time from the patient for analysis using wireless hand held devices like digital otoscope, digital stethoscopes, ophthalmoscope, laryngoscope, nasolaryngoscope then the appropriate treatment can be recommended by the specialist.

\section{CONCLUSION}

WMSN has already gained major attention of the research community due to its wide range of applications. This paper provides an overview and detailed comparison of several renowned existing telemedicine architectures. A study of some of the existing challenges faced by WMSN applications, comparison of UWB and Zigbee, hence solutions to the high bandwidth demand in live telemedicine are also offered. Moreover, a new telemedicine architecture has been proposed that integrates WMSN with $4 \mathrm{G}$ cellular network to allow global services. The architecture incorporates monitoring of the physiological data of the patient and a video conferencing facility for face-to-face consultation between the patient and the specialist.

\section{REFERENCES}

[1] I.F. Akyildiz, T. Melodia, and K.R.Chowdhury, 2007. A Survey on wireless multimedia sensor networks, Computer Networks (Elsevier) J., vol. 51, pp. 921-960.

[2] World Health Organization (WHO). 2010. Report on the second global survey on eHealth. TELEMEDICINE Opportunities and developments in Member States. Global Observatory for eHealth series - Volume 2.

[3] Adnan .I. Al Rabea. 2012. Using Wireless Sensor Networks for Managing Telemedicine Applications. International Conference on System Engineering and Modeling (ICSEM 2012) IACSIT Press, Singapore.

[4] Ko J., Lim J.H., Chen Y., Musaloiu-E. R., Terzis A., Masson G.M. MEDiSN: Medical Emergency Detection in Sensor Networks. ACM Trans. Embed. Comput. Syst. 2010; 10:1-29. 
[5] Pardeep K., Hoon-Jae L: Security Issues in Healthcare Applications Using Wireless Medical Sensor Networks: A Survey. MDPI Sensors (ISSN 1424-8220; CODEN: SENSC9), 2012; 12(1): 55-91. 22 December 2011

[6] Lorincz K., Malan D.J., Fulford-Jones T.R.F., Nawoj A., Clavel A., Shayder V., Mainland G., Welsh M. Sensor Networks for Emergency Response: Challenges and Opportunities. ," IEEE Pervasive Computing, vol. 3, no. 4 pp. 16-23, Oct.-Dec. 2004, doi:10.1109/MPRV.2004.18

[7] Hu F, Jiang M, Celentano L, Xiao Y. Robust medical ad hoc sensor networks (MASN) with wavelet-based ECG data mining. Ad Hoc. 2008;6:986-1012.

[8] Wood A., Virone G., Doan T., Cao Q., Selavo L., Wu Y., Fang L., He Z., Lin S., Stankovic J. ALARM-NET: Wireless Sensor Networks for Assisted-Living and Residential Monitoring. Department of Computer Science, University of Virginia; Charlottesville, VA, USA: 2006. Technical Report CS-2006-01;

[9] Chakravorty R. A Programmable Service Architecture for Mobile Medical Care. Proceedings of 4th Annual
IEEE International Conference on Pervasive Computing and Communication Workshop (PERSOMW'06); Pisa, Italy. 13-1 March 2006.

[10] Wimedia Alliance, www.wimedia.org/

[11] Jianli Pan, Prof. Raj jain. 2008. Survey paper. Medical applications of UWB. http://www.cse.wustl.edu/ jain /cse574-08/ftp/uwb/index.html. Last accessed 2013.

[12] D. Niyato, E. Hossain, and J. Diamond, "IEEE 802.16/WiMAX-based broadband wireless access and its application for telemedicine/e-health services [Accepted from Open Call]," Wireless Communications, IEEE [see also IEEE Personal Communications], vol. 14, pp. 72-83, 2007.

[13] Jin-Shyan Lee, Yu-Wei Su, and Chung-Chou Shen. 2007. A Comparative Study of Wireless Protocols: Bluetooth, UWB, ZigBee, and Wi-Fi. 33rd Annual Conference of the IEEE Industrial Electronics Society (IECON).

[14] Yuechun Chu and Aura Ganz. 2006. Mobile Telemedicine Systems Using 3G Wireless Networks. Report. University of Massachusetts. 